\title{
О.А. Кравченко
}

\section{«СКАЗКА О ЦАРЕВИЧЕ ХЛОРЕ»: ПУТИ РАЗВИТИЯ ЕЕ ОБРАЗНО-АЛЛЕГОРИЧЕСКОГО СТРОЯ В ОДЕ Г.Р. ДЕРЖАВИНА «ФЕЛИЦА»}

В статье исследуется характер творческого воздействия сказки Екатерины II на поэтику оды Г.Р. Державина "Фелица». Отмечается, что спеичфика одического высказывания Державина предзадана ситуачией творческого диалога с адресатом оды, порождаюшим жанровое новаторство. Дидактическая направленность сказки-претекста обретает в оде одновременно сатирический и сакральный векторы, что позволяет говорить не только о мотивной связи произведений, но и об утверждении общей для них идеи человечности как высшей добродетели.

Ключевые слова: Екатерина II, Державин, сказка, ода, сатира, жанр.

«Сказка о царевиче Хлоре», написанная Екатериной II для внуков Александра и Константина, была одним из самых популярных произведений императрицы. Отдельными книжками сказка вышла в 1781, 1782 и 1783 гг. Причем в 1783 г. по распоряжению директора Императорской Академии наук княгини Е.Р. Дашковой было напечатано «800 экз. на российском языке и 400 экз. с приобщением греческого перевода» [1. С. 338]. В «Сказке о царевиче Хлоре» ярко отразились идеалы эпохи Просвещения, и в то же время сама она стала своеобразным претекстом для ряда произведений XVIII в. Между тем и сама сказка, и порожденные ею интертекстуальные связи до сих пор исследованы недостаточно. Можно указать лишь на работы О.С. Карандашовой, раскрывающие различные аспекты интерпретации произведений Екатерины для детей: «Сказки о царевиче Хлоре» и «Сказки о царевиче Фивее» $[2,3,4]$. Что же касается того определяющего влияния, которое оказала первая сказка императрицы по поэтику оды Г.Р. Державина «Фелица», то здесь приходится говорить лишь о констатации самого факта державинского «отклика» на образный строй сказки. При этом даже в монографических исследованиях допускаются фактографические неточности. Так, например, И. Клейн пишет следующее: «...в 1781 году в печати появляется написанная самой императрицей <...> стилизованная в народном духе Сказка о царевиче Хлоре; ее вторая сказка «Сказка о царевиче Фивее позднее 
используется Державиным в Фелице» [5. С. 474]. Эта «путаница» служит лишним доказательством актуальности разговора о глубоких связях оды «Фелица» со «Сказкой о царевиче Хлоре»; прояснение которых и является задачей настоящей статьи.

Зачин сказки задает условно-историческое время: «До времени Кия, Князя Киевского, жил да был в России Царь...» [6. С. 118]. У Царя и Царицы родился сын - «дивное дитя» царевич Хлор. Слух о чудесном ребенке, который «сколь был красив, столь же был умён и жив», проник в чужие земли. И тогда Хан Киргизский, кочующий по дикой степи, захотел испытать дитя. Он выкрал царевича Хлора и велел ему найти «цветок розу без шипов, что не колется».

По закону волшебной сказки у Хлора появляется помощник ханская дочь Фелица, бывшая замужем за Брюзгой-Султаном. Брюзга «никогда не смеялся и серживался на других за улыбку, Ханша же была нрава веселого и весьма любезна» [6. С. 119]. Фелица предупреждает Хлора о различных трудностях пути и дает в провожатые своего сына. Простившись с Фелицей, царевич сквозь калитку входит в «превеликий зверинец». Именно так называет Екатерина то условное пространство, на котором разворачиваются поиски цветка - символа добродетели. Ханский зверинец - это собрание человеческих слабостей и пороков, здесь Хлор проходит нравственные испытания под руководством Рассудка, сына Фелицы. Сначала путникам встречаются люди, проводящие жизнь в веселиях, «безсчетных забавах», сопряженных, однако, «со множеством скук». Хлор не соглашается на их уговоры остаться и разделить безмятежное счастье. Новым препятствием на пути к добродетели становится встреча с Лентягом Мурзой. Лентяг возлежит на пуховых подушках, приказывает принести гостям «трубки курительные и кофе». Царевич от всего отказывается, но хочет отведать винограда из угощений Лентяги, однако непреклонный Рассудок напоминает ему о заветной цели. Переночевав в крестьянском доме, герои продолжают путешествие, но утомленный Хлор сворачивает с прямого пути. Он заходит на рынок, где все заняты торгом и меною. Царевич теряется среди телег и плачет от обиды на грубое обращение. Однако Рассудок-провожатый не покидает ребёнка. По узкой каменистой тропке они взбираются на гору и с помощью двух стариков - Честности и Правды - добираются до вершины горы. Здесь Хлор срывает цветок добродетели. Тут же в горном храме заиграли на трубах и литаврах, «и разнесся 
повсюду слух, что Царевич Хлор сыскал в таких молодых летах розу без шипов, которая не колется» [6. С. 126]. С тех пор все люди любили царевича, а он час от часу укреплялся в добродетели.

Как видим, сочинение императрицы в трансформированно-фольклорных образах утверждало просветительский идеал добродетельного монарха и нацеливало на воспитание честного, правдивого, справедливого и добродетельного человека. Механизмы указанных трансформаций детально прослежены в статье О.С. Карандашовой «Фольклорные традиции и черты литературности в сказках Екатерины II для детей». В частности, отмечается функциональная близость хитрого Хана, похитившего царевича, с образами Кощея и Змея. Однако герой-антагонист в сказке Екатерины лишен фантастичности, «Хан не является воплощением низкого, злого и враждебного всему живому, он лишь человек, хотя и подверженный порокам» [4. С. 48]. Интересна также предложенная трактовка образа Фелицы как варианта фольклорной Бабы-Яги, дающей жизненно необходимые для путника советы. Однако следует признать, что фольклорные схемы играют здесь лишь второстепенную роль, подчиняясь задаче создания философской аллегории. В образах розы, дороги, горы, Хлора и Фелицы (чьи имена символизируют нравственную чистоту и счастье), Рассудка, Правды и Справедливости утверждает себя характерная для поэтики классицизма тенденция создания аллегорической эмблематичности.

Можно говорить о том, что именно в сказке Екатерины добродетель как главное - человеческое, а не специально монаршее - достоинство правителя обретает конкретно-чувственную форму прекрасного цветка. Мы при этом полагаем, что сама идея человечности как высшей ценности восходит к Державину. В 1779 г., за два года до появления «Сказки о царевиче Хлоре», Г.Р. Державин написал оду в честь рождения внука Екатерины великого князя Александра (будущего императора), переделанную несколько позднее в «Стихи на рождение в Севере порфирородного отрока». В «Стихах...» не только произошла кардинальная трансформация оды: использование хореического размера вместо нормативного четырехстопного ямба, обытовление античных образов, особая позиция лирического героя, скорее пребывающего в замешательстве, чем горящего «пермесским жаром». Важнее то, что в «Стихах...» впервые человеческая добродетель монарха выступает своеобразным смысловым центром поэтической ситуации. Порфирородное дитя получает от слетающихся к его колыбели гениев все полагающиеся царственному младенцу дары: 
«гром <..> предбудущих побед», украшающие свет художества и науки, «сияние порфир», «спокойствие и мир», «разум, духа высоту» [7. С. 88].

Но самый главный дар, выбивающийся из ряда царских «совершенств», приносит последний из гостей, и этот дар - добродетель человечности:

Но последний, добродетель

Зарождаючи в нем, рек:

Будь страстей твоих владетель,

Будь на троне человек! [7. С. 89].

Таким образом, впервые слово «человек» как настоящий предмет поэзии произнес именно Державин. Это позволяет предположить, что творческий диалог Екатерины и Державина не исчерпывается сказочно-одическим образом Фелицы, но восходит к новаторским стихам Державина «На рождение в Севере порфирородного отрока».

Екатерина-писательница, чуткая к художественным тенденциям эпохи, образно варьирует и углубляет смыслы человечности как добродетели. Причем обращается для этого не только к форме сказки, но и к такой разновидности детского чтения, как азбука. Написанная Екатериной также для ее внуков «Начальная азбука с гражданским учением» содержит наставления в добродетельном поведении.

Подхватив в свою очередь сюжет «Сказки о царевиче Хлоре» и слегка усилив ее восточный колорит, Г. Р. Державин в 1872 г. написал оду Екатерине от имени «некоторого татарского мурзы», обыграв тем самым предание о происхождении своего рода от татарского мурзы Багрима. В объяснениях к оде ее автор отмечал, что назвал Екатерину киргиз-кайсацкою царевною еще и потому, что у него были деревни в тогдашней оренбургской области, по соседству с киргизскою ордою, подвластною императрице. В первой публикации ода Державина «Фелица» называлась так: «Ода к премудрой киргиз-кайсацкой царевне Фелице, написанная некоторым татарским мурзою, издавна поселившимся в Москве, а живущим по делам своим в СанктПетербурге. Переведена с арабского языка».

Эта литературная мистификация стала не просто восхвалением монархини, но попыткой развития творческого диалога. Вячеслав Ходасевич в своей книге о Державине так обрисовал состояние одической пресыщенности, которое переживала Екатерина ко времени появления «Фелицы»: «Прежние похвалы Державина, в сущности более громкие и глубокие, нежели те, которые заключались в “Фелице”, 
она, вероятно, тоже читала. Но они даже не запомнились - потонули в хоре привычной лести. А над “Фелицей” она несколько раз принималась плакать. “Как дура плачу”, - сказала Дашковой» [8. С. 130].

«Почему же она была так растрогана?» - задается вопросом Вяч. Ходасевич и объясняет это тем, что Екатерина устала от торжественных штампов и была рада увидеть себя не только государыней, но и живой женщиной, с ее привычками и склонностями. При всей справедливости этих объяснений, пожалуй, следует учитывать также и то, в «Фелице» императрица увидела непосредственную реакцию на собственную поэтическую личность, на Екатерину-писательницу. Возможно, эта ситуация сотворчества и была решающей для успеха столь неоднозначной по своей эстетической архитектонике державинской оды. Понимая, что Екатерина равнодушна к стихам и поэтическая красота для нее «приятна, сладостна, полезна, / Как летом вкусный лимонад», Державин пленяет Екатерину ее же сказкой, укрупнив и исторически конкретизировав каждый «лепесток» розы добродетели и придав выразительность многочисленным образам зверинца человеческих пороков.

История публикации державинской оды была сопряжена с опасениями негативной реакции узнаваемо и насмешливо описанных в ней первых лиц государства: Г. Потемкина, А. Орлова, П. Панина, С. Нарышкина. Когда «по секрету» передаваемая из уст в уста ода дошла, наконец, до Потемкина и он потребовал ее полный текст, Державин был готов к самому худшему исходу событий и несколько месяцев томился неопределенностью своего положения. Между тем княгиня Дашкова весной 1873 г. поместила «Фелицу» в первой книжке только что учрежденного «Собеседника любителей российского слова». Державин, страшившийся опалы, получил в награду от Екатерины осыпанную бриллиантами золотую табакерку с пятьюстами червонцами.

Этот знак высшего монаршего признания поставил Державина в ряд знаменитостей и наиболее приближенных к императрице вельмож. Как писал Ходасевич, Екатерина «разом ставила Державина очень высоко, как бы вводила его в круг людей, с которыми императрица шутит» [8. С. 132].

\footnotetext{
${ }^{1}$ Вяч. Ходасевич так описывает поэтическую холодность Екатерины: «Она не слишком любила стихи, не много в них понимала и самого вещества поэзии не чувствовала. Вопросы чистой поэзии не занимали ее. При всей любви к литературным упражнениям, она не умела составить ни одного стиха и сама в том признавалась...» [8. С. 130].
} 
Успех Державина во многом был предзадан сочетанием прославления и порицания, одического хвалебного пафоса и снижающего сатирического осмеяния. Но в то же время он определялся точным попаданием в «поэтическую тональность» Екатерины. О.Б. Лебедева подчеркивает, что «опосредованное обращение к императрице через ее художественный текст дало Державину возможность избежать протокольно-одического, возвышенного тона обращения к высочайшей особе» [9. С. 287]. Державин начинает свое произведение не с позиции одописца, а с позиции человека, отправляющегося, подобно царевичу Хлору, на поиски добродетели и просящего наставленья премудрой Ханши:

\author{
Богоподобная царевна \\ Киргиз-Кайсацкия орды! \\ Которой мудрость несравненна \\ Открыла верные следы \\ Царевичу младому Хлору \\ Взойти на ту высоку гору, \\ Где роза без шипов растет, \\ Где добродетель обитает, - \\ Она мой дух и ум пленяет, \\ Подай найти ее совет [7. С. 97].
}

Дальнейшее смысловое развертывание строится на контрастном сопоставлении добродетели и порока, причем воплощением первой является сама Фелица-Екатерина. Таким образом, автор снимает ситуацию поиска, трудного пути к желанной цели. Добродетель уже предстала перед лирическим героем и читателями, и потому высказывание строится как перечисление всех достоинств ее носительницы и осуждение всех пороков, свойственных лирическому герою - мурзе. В обоих случаях, несмотря на принятую поэтическую условность, Державин старается быть максимально конкретным, указывая на придворные, политические, военные реалии времени. Но в то же время ему важно сохранять близость к тексту екатерининской сказки, удерживать перед умственным взором читателей ее образно-символический строй.

Так, можно привести многочисленные примеры аллюзивных отсылок. Это, в частности, упоминание «трубок курительных и кофе», которыми Лентяг в сказке хотел угостить царевича Хлора и его провожатого. Но если сказочные герои «табаку не курят» и «кофе не пьют», то одический «раб прихотей» мурза говорит о себе противоположное: 
А я, проспавши до полудни,

Курю табак и кофе пью;

Преображая в праздник будни,

Кружу в химерах мысль мою... [7. С. 98]

(здесь и далее курсив в цитатах наш. - O.К.).

Кружение мысли также можно считать трансформированной сказочной ситуацией, отсылающей и к непрямым путям, и к пляшущим в кругу праздно веселящимся людям.

Державин-одописец использует собственные имена как нарицательные, придавая сказке статус литературного топоса:

$$
\begin{aligned}
& \text { Между лентяем и брюзгой }{ }^{1}, \\
& \text { Между тщеславьем и пороком } \\
& \text { Нашел кто разве ненароком } \\
& \text { Путь добродетели прямой [7. С. 100]. }
\end{aligned}
$$

Однако не собственно указанными аллюзиями задается диалогическая связь сказки и оды. Здесь важно появление одического слова как высказывания, претендующего на непререкаемый авторитет, всеобщую значимость и безусловность утверждаемых смыслов. То, что первоначально предназначалось для детской комнаты и камерного домашнего чтения, обретает ораторские обертоны. Державин, таким образом, переводит произведение Екатерины совершенно в иной регистр. Причем в новом звучании никак не ослабляются смысловые пружины, задававшие ход сказочному повествованию, напротив, они словно наращивают силу своих импульсов.

Композиционное построение оды также отражает зависимость от екатерининского текста-источника. Ода условно разделяется на две части, каждая из которых содержит вопрошание о заветной розе. В первой строфе это строки о царевиче, взошедшем на гору, «где роза без шипов растет, / где добродетель обитает», в двенадцатой строфе сетования на человеческие страсти и заблуждения, переходящие в вопрос: «Где ж добродетель обитает? / Где роза без шипов растет?»

В первой части оды лирический герой мурза, как бы занимая положение Хлора, просит Фелицу «подать наставленье». Но тут же признается, что не в силах ему следовать: «Мятясь житейской суетою, / Сегодня властвую собою, / А завтра прихотям я раб». Разговор о дос-

${ }^{1}$ В Объяснениях к «Фелице» Державин пишет: «Сколько известно, разумела она под первым кн. Потемкина, а под другим кн. Вяземского, потому что первый, как выше сказано, вел ленивую и роскошную жизнь, а второй часто брюзжал, когда у него, как управляющего казной, денег требовали» (цит. по: [7. С. 376]). 
тоинствах Фелицы здесь призван оттенить пороки мурзы: «Подобно в карты не играешь, / Как я, от утра до утра». Воздав похвалы кротости царицы и описав распорядок ее дня, мурза переводит взгляд на самого себя, актуализируя в одическом высказывании тот эпизод «Сказки...», где Хлор и Рассудок оказываются среди приживальщиков Лентяги. Многие из них подобно Хлору отправлялись на поиски розы без шипов, но, не преодолев соблазнов пути, так и остались жить в праздности и пороке. Таким образом, сатирическая часть оды является своеобразным развертыванием эпизода у Лентяги и рассматриванием обитателей человеческого «зверинца».

Именно сатирическая часть вызывала державинские опасения в гневе екатерининских вельмож, без труда узнававших собственные портреты. Отметим, что «личностно» реагировала на содержащуюся в оде сатиру и сама Екатерина, адресно рассылая оттиски «Фелицы» всем тем, чьи «слабости» в ней были описаны. Однако вряд ли можно говорить здесь о Державине как злом сатирике-обличителе. Живо описывая пороки вельмож, он не обходит стороной и почти интимные подробности собственных домашних занятий, отмечая в объяснениях к оде, что «сей куплет относится вообще до старинных обычаев и забав русских» [7. С. 376]:

$$
\begin{aligned}
& \text { Иль, сидя дома, я прокажу, } \\
& \text { Играя в дураки с женой; } \\
& \text { То с ней на голубятню лажу, } \\
& \text { То в жмурки резвимся порой; } \\
& \text { То в свайку с нею веселюся, } \\
& \text { То ею в голове ищуся... [7. С. 376]. }
\end{aligned}
$$

Таким образом, подразумевая в сатирическом описании конкретных людей, Державин все же ориентируется на общие законы человеческого существования, и в этом смысле сказка-претекст как раз и предстает воплощением должного бытийного плана. Утверждая универсальный характер заложенных в сказке положений, Державин усиливает их формулой сакрального текста: «всякий человек есть ложь» ${ }^{1}$.

Сатирическая часть оды воссоздает тот особый порочный фон, на котором Фелица-Екатерина предстает счастливым исключением из

1 Державин цитирует 115-й псалом. Более подробно о библейских аллюзиях и христианской доминанте «Фелицы» см. статью С.А. Саловой «Метафизические аспекты в оде Г.Р. Державина “Фелица”» [10]. 
правила. Она сама и есть воплощение искомой добродетели, созидающей счастье:

Из разногласия согласье

И из страстей свирепых счастье

Ты можешь только созидать... [7. С. 101].

В композиционном отношении сатирическое обличение «зверинца» уравновешивается патетическим прославлением добродетельной монархини. Но и здесь также Державин старается не выпускать из поля зрения сказку, однако уже не в ее содержательном, а в назидательном аспекте. Таким образом, к числу добродетелей причисляется сама морализаторская направленность творчества императрицы. Не уподобляясь предшествующим российским правителям, Екатерина создает сказки и азбуки, воспитывая своих подданных в духе кротости и незлобивости:

В твои от дел отдохновеньи

Ты пишешь в сказках поученьи, И Хлору в азбуке твердишь:

"Не делай ничего худого, И самого сатира злого Лжецом презренным сотворишь" [7. С. 102].

Интересно отметить тот факт, что воздействие сказки на оду придало последней черты интимности, создало иллюзию близкого знакомства автора с адресатом. В книге Вяч. Ходасевича эта ситуация получает следующее художественное воплощение: «...при всей идеальности портрет и на самом деле был очень схож. Екатерина считала, что безымянный автор разгадал ее всю - от больших добродетелей до маленьких слабостей. “Кто бы меня так хорошо знал?” - в слезах спрашивала она у Дашковой» [8. С. 132].

Между тем Державин был лично представлен императрице уже после получения от нее знаменитой золотой табакерки. Но даже учитывая художественную условность воспроизводимой Вяч. Ходасевичем императорской реакции на «Фелицу», следует задаться вопросом о том, что заставило предполагать близкое знакомство одописца с Екатериной. Мы считаем, что здесь снова-таки проявилось влияние сказки: предзаданная ею установка на близость дистанции и «неофициальность» общения вылилась в обытовленный одический образ. Причем, как подчеркивает О.Б. Лебедева, сниженно-бытовой образ порока был традиционен для сатиры, в то время как «бытового 
образа добродетели, да еще и венценосной, русская литература до Державина принципиально не допускала» [9. С. 288]. Бытовая конкретность и достоверность облика Екатерины вытеснила абстрактную схему идеального монарха не без предшествующего усилия со стороны самой Екатерины предстать живым человеком в семейном окружении, бабушкой, сочиняющей сказки для внуков. Эта сказочная модальность образа императрицы и была столь успешно разработана Державиным.

В оде заслуживает внимания еще один момент, сопряженный с семейно-бытовым амплуа монархини. Воспевая такие ее качества, как скромность, любезность и приятность в обращении, Державин пишет:

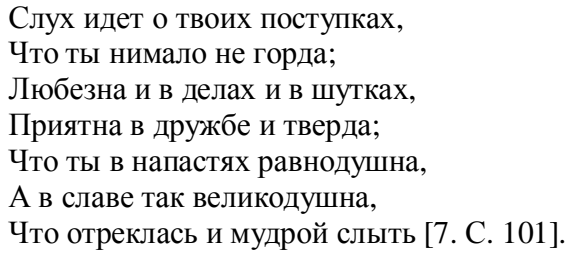

Это отречение заслуживает особого комментария. Речь идет о том, что в 1767 г. Комиссия по составлению Нового Уложения приняла решение о поднесении Екатерине II титула «Великой Екатерины, Премудрой и Матери Отечества». Императрица отклонила титул за его «преждевременностью». Однако через несколько дней она вновь приняла депутатов Комиссии, вторично отказалась от именования «Великой и Премудрой», но оставила за собой титул «Матери Отечества» (см.: [11. С. 85]). Державин, говоря о великодушии Екатерины, имплицитно вводит сопряженную с ней тему семейственности, охватывающей в данном случае целое государство.

Таким образом, Державин сочетает интимные и государственнопатетические оттенки в образе Фелицы. Будучи одописцем, он видит главную цель в восхвалении и возвеличении монархини. Этим объясняется осуществляемая в финале «Фелицы» смысловая амплификация: деятельность государыни в ее добродетельной заботе о своих подданных приравнивается к мироустроительной силе Бога. Поэт называет императрицу кротким и мирным ангелом, ниспосланным с небес, и взывает к высшим силам: 


\section{Небесные прошу я силы, \\ Да, их простря сафирны крылы, \\ Невидимо тебя хранят \\ От всех болезней, зол и скуки; \\ Да дел твоих в потомстве звуки, \\ Как в небе звезды, возблестят [7. С. 104].}

В финальных образах неба, звезд, сияющего трона выстраивается смысловая вертикаль, соотносимая с восхождением Хлора на вершину горы. Вертикальная направленность движения утверждает поэтическое усилие духовного возвышения. Интересно отметить, что своеобразным продолжением этого сказочно-одического вектора стал построенный в 1780-е гг. по проекту архитектора Н.А. Львова «Храм Розы без шипов», воспроизводящий в Павловске топографию «Сказки о царевиче Хлоре».

Сама же державинская ода оказывается специфическим типом поэтического высказывания, осуществляющимся в напряженном взаимодействии сказочного и ораторского жанров. Снимая мотив странствия, Державин тем не менее сохраняет актуальность мотива поиска добродетели, реализуя его и на содержательно-стилевом, и на композиционном уровне произведения. Образно-аллегорический строй «Сказки о царевиче Хлоре» преломлен в конкретно-исторической ситуации создания «Фелицы», не утрачивая при этом глубины и действенности заложенных нравственно-воспитательных идей.

Отметим в заключение, что в сознании целой эпохи творческий диалог Екатерины Великой и Г.Р. Державина закрепился как одно из самых значимых духовных событий. Уже после смерти императрицы, работая над проектом устройства Сената при дворе Александра I, Державин разрабатывал принцип централизации законодательной власти в руках монарха. При этом залогом уважения к закону оказывалась исключительно личная добродетель монарха. Вяч. Ходасевич по этому поводу пишет: «Недаром старался он в ту пору увлечь Александра идеальным портретом Царевича Хлора, как некогда соблазнял Екатерину изображением Фелицы» [8. C. 224]. И хотя предложения Державина были отклонены, Александр запомнил их, свидетельством чего стало награждение Державина орденом Александра Невского.

Дальнейшие исследования влияния «Сказки о царевиче Хлоре» на развитие русской литературы XVIII в. могли бы вовлечь в себя и барочно-классицистический роман М. Хераскова «Кадм и Гармония» с его идеей провиденциального пути идеального правителя, 
и сказку Аксакова «Аленький цветочек», актуализирующую мотив поиска заветного цветка. В целом возрождение значения полузабытого произведения Екатерины II позволит обогатить картину жанрового развития, а также осмыслить механизм жанровых трансформаций сказочных мотивов.

\section{Литература}

1. Сводный каталог русской книги XVIII (1725-1800). М., 1962. Т. 1.

2. Карандашова О.С. Взгляды Екатерины II на воспитание в сказках для детей // Детская литература и воспитание. Тверь, 2004. С. 113-118.

3. Карандашова О.С. Идеи Просвещения в сказках Екатерины II для детей («Сказка о царевиче Хлоре», «Сказка о царевиче Фивее») // Вестн. Твер. гос. ун-та. Сер. Филология. 2005. № 7 (13). Вып. 3. С. 4-11.

4. Карандашова O.C. Фольклорные традиции и черты литературности в сказках Екатерины II для детей // Вестн. Твер. гос. ун-та. Сер. Филология. 2013. Вып. 2. С. 4552.

5. Клейн И. Пути культурного импорта: Труды по русской литературе XVIII века. М.: Языки славянской культуры, 2005. 576 с. (Studia philologica).

6. Екатерина II. Сочинения. М.: Современник, 1990. 557c.

7. Державин Г.Р. Сочинения. М., 1957. 501 с.

8. Ходасевич Вяч. Державин. М.: Книга, 1988. 384 с.

9. Лебедева О.Б. История русской литературы XVIII века: учеб. М.: Высш. шк.: Изд. Центр «Академия», 2000. 415 с.

10. Салова С.А. Метафизические аспекты в оде Г.Р. Державина «Фелица» // Поэтика русской и зарубежной литературы. Уфа, 1998. С. 37-50.

11. Екатерина Великая и Москва: каталог выставки. М., 1997. С. 85.

THE STORY OF TSAREVICH CHLOR: ON DEVELOPMENT OF THE FIGURATIVE AND ALLEGORICAL SYSTEM IN DERZHAVIN'S ODE TO FELICE

Imagology and Comparative Studies, 2015, 1(3), pp. 91-104. DOI: 10.17223/24099554/3/6

Kravchenko Oksana A. Donetsk National University (Donetsk, Ukraine). E-mail: 1234oksana@rambler.ru

Keywords: Catherine II, Derzhavin, tale, ode, satire, genre.

The article investigates the impact of Catherine II's fairy tale on the poetics of Derzhavin's Ode to Felice. Catherine II's fairy tale in its transformed folklore images affirms the Enlightenment ideal of the virtuous monarch and aims to bring up an honest, truthful, just and virtuous man. The fairy tale reflects Derzhavin's innovative position of Man as the subject of poetry. It is suggested that the creative dialogue between Catherine and Derzhavin be not limited to the fairy-tale and odic Felice, but go further to the innovative Derzhavin's poems "Birth of a North Crowned Lad".

The success of Derzhavin's ode, with its ambiguous aesthetic architectonics, was predetermined by the fact that Ode to Felice was seen by the Empress as an immediate reaction to her own poetic identity, to Catherine-writer. It was not only the combination of praise and blame, odic laudatory pathos and satirical ridicule, but the exact assonance with the Catherine's 'poetic tone' that promoted Derzhavin to the Empress's poet-confidant. 
However, the fairy-tale orientation outlined the genre innovation: Derzhavin begins his work not from the position of an ode writer, but from the perspective of a man who, like Tsarevich Chlor, goes in search of virtues and asks the Khan's Wise to instruct him. The further semantic development is based on the contrast between virtues and vice, where the former is embodied by Felice-Catherine II. Derzhavin does not describe the situation of search or a difficult road to the desired goal. The lyric hero and readers can see the embodiment of virtue; therefore the statement lists all the advantages of the virtue-bearer and the condemnation of all the vices inherent to the lyrical hero - Mirza. In both cases, despite the poetic convention, Derzhavin tries to be as specific as possible, including the court, political and military realities of the time. At the same time it is important for him to keep close to the text of Catherine's fairy tale with its imagery and symbolism.

Numerous allusions to the fairy-tale imagery (the menagerie of human vices, road, mountain, rose), the use of proper names as common (Grumpy, Lentyag), and compositional peculiarities make possible to consider the fairy tale not only as an odic pretext, but as an ontological universal primary text.

Having created the household image of the crowned virtue for the first time, Derzhavin reformed the genre of ode that traditionally followed the abstract scheme of an ideal monarch. It was possible due to Catherine's previous efforts to be a real person within her family circle, a grandmother telling fairy tales to her grandchildren. This fairy-tale modality of the Empress's image was successfully developed by Derzhavin. However, Derzhavin combines the intimate and public pathetic shades in Felice's image. As an ode writer, he sees the main goal in praise and glorification of the monarch. It explains the semantic amplification in the final of Ode to Felice: the Empress's virtuous care of her subjects is equivalent to God's dispensations.

Thus, Derzhavin's ode is a particular type of poetic expression that implies an intense interaction between the fairy-tale and rhetorical genres. Removing the motif of journey, Derzhavin, nonetheless, preserves the motif of search in the content, style and composition. The imagery and allegory of The Story of Tsarevich Chlor is reworked in the certain historical situation of The Ode to Felice, without losing the depth and effectiveness of its inherent moral and educational ideas.

\section{References}

1. The USSR State Library. (1962) Svodnyy katalog russkoy knigi XVIII (1725-1800) [The Summary Catalog of Russian Books of the 18th Century (1725-1800)]. Vol. 1. Moscow: The USSR State Library.

2. Karandashova, O.S. (2004) Vzglyady Ekateriny II na vospitanie v skazkakh dlya detey [Catherine II's views on education in fairy tales for children]. In: Detskaya literatura $i$ vospitanie [Children's Literature and Education]. Tver: Tver State University. pp. 113-118.

3. Karandashova, O.S. (2005) Idei Prosveshcheniya v skazkakh Ekateriny II dlya detey ("Skazka o tsareviche Khlore", "Skazka o tsareviche Fivee") [The Enlightenment ideas of Catherine II in fairy tales for children ("The Story of Tsarevich Chlor", "The Story of Tsarevich Fivey")]. Vestnik TvGU. Ser. Filologiya. 7 (13). pp. 4-11.

4. Karandashova, O.S. (2013) Fol'klornye traditsii i cherty literaturnosti v skazkakh Ekateriny II dlya detey [The folklore traditions and characteristics of literary Catherine II's fairy tales for children]. Vestnik TvGU. Ser. Filologiya. 2. pp. 45-52.

5. Klein, I. (2005) Puti kul'turnogo importa: Trudy po russkoy literature XVIII veka [The Ways of Cultural Import: Proceedings on Russian Literature of the 18th Century]. Moscow: Yazyki slavyanskoy kul'tury. 
6. Catherine II. (1990) Sochineniya [Works]. Moscow: Sovremennik.

7. Derzhavin, G.R. (1957) Sochineniya [Works]. Moscow.

8. Khodasevich, Vyach. (1988) Derzhavin. Moscow: Kniga.

9. Lebedeva, O.B. (2000) Istoriya russkoy literatury XVIII veka [The History of Russian Literature of the 18th Century]. Moscow: Akademiya.

10. Salova, S.A. (1998) Metafizicheskie aspekty v ode G. R. Derzhavina "Felitsa" [Metaphysical aspects of Derzhavin's "Ode to Felice"]. In: Poetika russkoy $i$ zarubezhnoy literatury [The Poetics of Russian and Foreign Literature]. Ufa: Gilem. pp. 37-50.

11. Markina, L.A. (ed.) (1997) Ekaterina Velikaya i Moskva [Catherine the Great and Moscow]. Moscow: The Tretyakov Gallery. p. 85. 